\title{
Dangerous liaisons? As the COVID-19 wave hits Africa with potential for novel transmission dynamics: a perspective
}

\author{
Willis Gwenzi ${ }^{1}$ (D)
}

Received: 24 June 2020 / Accepted: 15 December 2020 / Published online: 2 January 2021

(C) Springer-Verlag GmbH Germany, part of Springer Nature 2021

\section{Introduction}

The COVID-19 global pandemic was first reported in Wuhan, China, followed by subsequent outbreaks in other parts of Asia, Western Europe, and North America (Miller et al. 2020; Velavan and Meyer 2020). Towards the end of February 2020, the first case of COVID-19 was reported in Brazil, marking the arrival of the COVID-19 wave in South America (Miller et al. 2020). Recently, the COVID-19 wave has hit Africa, turning the continent into the next potential hotspot for the global pandemic. To date, significant outbreaks have been reported in all regions of Africa, including East Africa, West Africa, southern Africa, central Africa, and North Africa (Africa CDC 2020; Martinez-Alvarez et al. 2020). As of 6 August 2020, 1,007,366 confirmed cases of COVID-19 and 22,066 deaths have been reported in Africa, and the infections continue to rise rapidly (Africa CDC 2020). Southern Africa, with a total of 565,100 confirmed cases, accounts for slightly more than half (i.e., 56\%) of the cases in Africa. The World Health Organization predicts that up to 190,000 could die in Africa if COVID-19 is not controlled (WHO 2020c, d).

Severe acute respiratory syndrome coronavirus 2 (SARSCoV-2), the etiologic agent that causes COVID-19, is transmitted predominantly via respiratory droplets released by symptomatic and asymptomatic infected persons via coughing, sneezing, and through direct contact with contaminated surfaces (WHO 2020b, c). Accordingly, current control methods for minimizing transmission via these routes include wearing appropriate personal protective equipment (PPE),

Willis Gwenzi

wgwenzi@yahoo.co.uk; wgwenzi@agric.uz.ac.zw

1 Biosystems and Environmental Engineering Research Group, Department of Soil Science and Agricultural Engineering, Faculty of Agriculture, University of Zimbabwe, P.O. Box MP 167, Mount Pleasant, Harare, Zimbabwe practicing hand hygiene via frequent and regular hand washing, and social distancing based on national lockdowns and quarantines (WHO 2020b, c). Several recent studies have suggested the fecal-oral route as a potential transmission mode (Goh et al. 2020, Gu et al. 2020; Gwenzi 2020b; Heller et al. 2020; Hindson 2020). For example, the fecal-oral route transmission was discussed in detail in an earlier review paper focusing on low-income countries (Gwenzi 2020b). This is because SARS-CoV-2 RNA has been detected in the human gastrointestinal tract, stools, and even raw wastewater (Ahmed et al. 2020; Lodder and de Roda Husman 2020; Randazzo et al. 2020; Yeo et al. 2020).

The outbreak of COVID-19 in Africa, particularly in subSaharan Africa, is significant in a number of respects. First, the region experiences chronic poverty, and has poor social security and health care systems with limited capacity to cope with a pandemic of such magnitude. Second, the COVIDwave arrived during wintertime, when conditions are conducive for the transmission and persistence of SARS-CoV-2. Finally, the region experiences a variety of inherent risk factors predisposing humans to COVID-19. Hence, novel COVID-19 transmission modes via fecal contamination of drinking water and food sources, and human exposure via the fecal-oral route cannot be ruled out. However, an African perspective on the practical implications of the potential for novel transmission of COVID-19 and its potential interactions with the inherent socioeconomic drivers, risk factors, and challenges in Africa is still lacking. This perspective, which targets policy-makers, practitioners, aid agencies, and the research community, seeks to address this gap. Figure 1 summarizes the focus of the current perspective.

The current perspective posits that, collectively, these socioeconomic drivers, risk factors, and challenges, coupled with the highly infectious COVID-19 with a fatality rate of about $4 \%$ and a high risk for novel transmission, constitute "dangerous liaisons." In turn, this will result in adverse human health outcomes and long-lasting knock-on effects in fragile African countries. Hence, novel transmission dynamics 
Fig. 1 A summary of the COVID-19 characteristics and socioeconomic drivers, risk factors, challenges, and proposed additional safeguards in Africa

Dangerous liaisons in Africa?: COVID-19 $\mathrm{x}$ risk factors $\mathrm{x}$ drivers $\mathrm{x}$ challenges

a COVID-19:

Africa COVID-19 statistics: 7 Aug. 2020:

SARS-CoV-2 virus

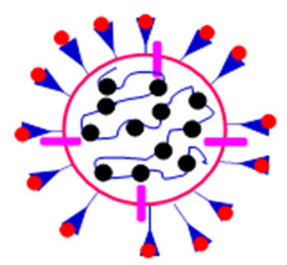

Characteristics:

- Infectious \& virulent

- Persistence

- Respiratory \& faecal shedding

- Conventional transmission: -Respiratory droplets -Direct contact

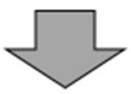

b Socio-economic drivers \& challenges:

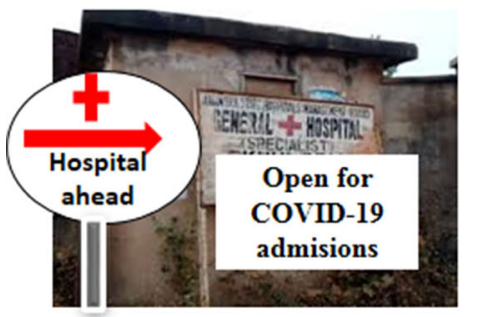

Poor health care \& social security systems

- Chronic poverty

- Unemployment

- Poor food hygiene

- \& safety practices

- Overcrowding due to critical shortage of goods \& services e.g, water, housing

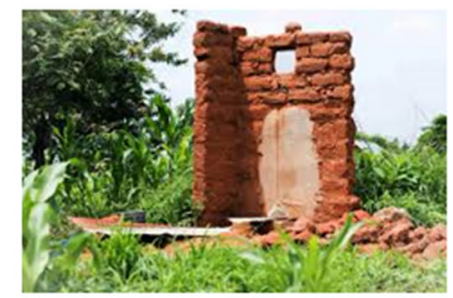

Poor sanitation infrastructure Time since first case deaths
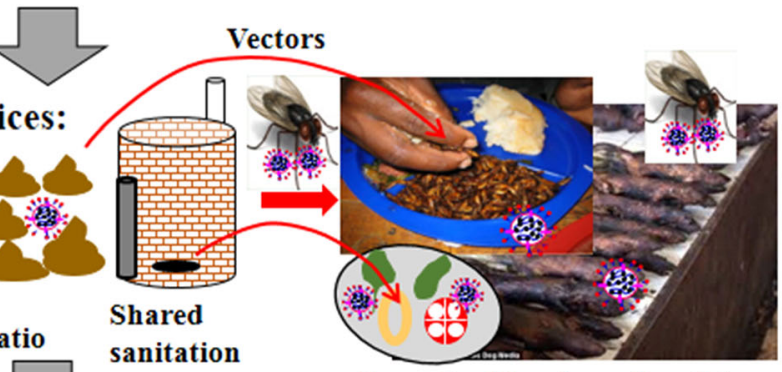

Poor food hygiene \& safety e.g., open and street vending

d Outcomes \& mitigation: systems

Novel COVID-19 transmission: Health \& social outcomes: Control \& Mitigation:

- Faecal-oral route

- Food cross-contamination

- Vector-mediated transmission In addition to conventional transmission modes
- Complex transmission

- High infections

- Synergistic interactions

with co-infections

- High fatalities

- Knock-on effects
- Consider novel transmission

- Additional safeguards

- Improve water, sanitation and hygiene

- Awareness campaigns and further safeguards should be considered and integrated into the current COVID-19 control measures. The purpose of this perspective is to draw the attention of the public, policy-makers, practitioners, and the research community to issues currently overlooked in the discussion on COVID-19 in Africa. First, novel transmission modes and their lines of supporting evidence are presented. The socioeconomic drivers, risk factors, and challenges predisposing humans in Africa to COVID-19 are discussed. Finally, the need to consider novel transmission dynamics and the corresponding additional safeguards is highlighted.
Notably, this perspective does not intend to downplay the critical role of COVID-19 transmission via the respiratory and direct contact routes and the associated mitigation methods based on hand hygiene, use of PPE, and social distancing. Instead, the current study presents a perspective on COVID-19 transmission dynamics and control methods in the African context, an aspect which is currently missing in the existing COVID-19 literature. Given that COVID-19 has now hit Africa, any perspectives on the topic are best shared in a timely and rapid manner, hence the current study. 


\section{COVID-19: risk factors, drivers, and challenges}

\section{Socioeconomic drivers}

Africa has markedly low economic development, evidenced by chronic poverty, unemployment, and a critical shortage of essential goods and services (Buheji et al. 2020; Mahler et al. 2020). Because of these shortages of goods and services, people literally queue for nearly everything (Jones 2019). This includes water, sanitation facilities, financial services (e.g., banking), public transport, shopping, and payment of utility bills, as well as personal registration and travel documents such as birth and death certificates, and passports. While some of these services are provided via online platforms in developed regions, such systems are either non-existent or unreliable in Africa. This results in overcrowding, making it difficult to consistently maintain social distancing.

Because of the low economic development in several African countries, there is a high flux of people among neighboring countries in search of employment opportunities, goods, and services (Moyo and Nshimbi 2020). Poor border control systems and highly porous national borders mean that illegal cross-border travel and human trafficking via undesignated entry points and subsequent deportations are common (Adepoju 2005; Truong 2005). Poor urban planning has led to informal settlements such as overcrowded slums and squatter camps (Durand-Lasserve 2006), while political instability and humanitarian disasters have forced people into refugee camps (McNatt 2020). Unemployment is very high; thus the bulk of the population relies on informal jobs such as vending and manual jobs for income and livelihood. With low income and poor social security systems, COVID-19 control measures such as self-quarantine, social distancing, and use of PPE present significant challenges in Africa.

Literacy levels in Africa are low, which accounts for a number of misconceptions, myths, and poor understanding of the health risks posed by COVID-19 (Abuya et al. 2020; Chersich et al. 2020; Nachega et al. 2020a). Anecdotal evidence suggests that several perceptions, myths, and attitudes exist in some African countries. For example, some believe that native Black Africans are genetically resistant to COVID19. Hence, COVID-19 is perceived to affect people of specific racial descent and regions who are genetically predisposed to the disease. These myths and misconceptions may be attributed to the fact that significant outbreaks in Africa have generally lagged behind those in Asia, Europe, and South America (Miller et al. 2020; Nachega et al. 2020b). Such myths and misconception have no scientific basis, but may promote the transmission of COVID-19 and even delay implementation of control measures. Moreover, a lack of trust in public institutions and governance systems raises concerns about whether the public will strictly comply with government-imposed restrictions and mitigation measures (Costa 2020; Khemani
2020). Collectively, these socioeconomic factors have potential impacts on the COVID-19 transmission dynamics and effectiveness of control methods.

\section{Challenges}

Poor water, wastewater, and sanitation infrastructure A significant portion of the African population still lacks access to clean drinking water, wastewater treatment systems, and proper solid waste and sanitary facilities such as modern toilets (Fuente et al. 2020; Momberg et al. 2020). Hence, raw and partially treated wastewater from municipal sewer systems, health care facilities, on-site sanitation systems, and even funeral homes are directly discharged into surface and groundwater systems without prior treatment (Gwenzi 2020a, c). Lacking sanitary landfills and incinerators, hazardous solid wastes, including municipal wastes, and infectious materials from health care systems (Ali et al. 2017) and the funeral industry such as used PPE, dressings, and bandages are often co-mixed and disposed of in non-engineered waste dumps (Patwary et al. 2011). These practices increase the risk of COVID-19 transmission and drinking water contamination with SARS-CoV-2 and other human pathogens.

Because of lack of proper sanitation facilities, unimproved rudimentary methods such as pit latrines, poorly designed septic tanks, and open defecation are still common (Yiougo et al. 2011; Okullo et al. 2017). The World Health Organization (WHO) recommends the following with respect to the siting of on-site sanitation systems relative to drinking water sources: (1) a depth difference of at least $1.5 \mathrm{~m}$ between the groundwater table and the base of the on-site sanitation system, with larger values recommended for areas with highly porous sandy and gravelly substrate with higher hydraulic conductivity, and (2) a horizontal distance of at least $30 \mathrm{~m}$ between drinking water sources and on-site sanitation systems (Tilley et al. 2014; WHO 2020e). However, such recommendations are often not achievable in African settings, because the landholding per household is frequently too small to allow such physical distances. Hence, in reality, on-site sanitation systems are often closely juxtaposed with community water sources such as wetlands, wells, and boreholes (Beukes et al. 2017; Potgieter et al. 2020). Yet the bulk of the population in Africa lacking access to treated clean drinking water relies on untreated water from unprotected sources such as shallow hand-dug wells, rivers, and boreholes (Nguyen et al. 2014). Thus, the potential for fecal-oral route transmission of pathogens including SARS-CoV-2 could be higher than initially perceived. The recurrent outbreaks of waterborne diseases such as cholera and typhoid in several African countries support this notion (Gwenzi and Sanganyado 2019).

In some settings such as informal settlements, both water and on-site sanitation systems are shared by several households (Siminyu et al. 2017; Caruso and Freeman 2020). This 
causes overcrowding and increases the risk of community transmission of COVID-19. Overcrowding at such shared water and sanitation points makes social-distancing problematic. In densely populated settlements, community shared sanitation facilities are prone to overloading, which may in turn result in overflowing and spillage into drinking water sources. A recent review by Caruso and Freeman (2020) discussed the risks of COVID-19 transmission via shared sanitation facilities. In such facilities, SARS-CoV-2 transmission may occur via the following pathways: (1) airborne route through aerosolization of toilet wastewater or effluent during flushing, and (2) direct contact with contaminated surfaces, also known as fomites (Caruso and Freeman 2020). Surprisingly, the recent WHO (2020e) update on COVID-19 focusing on water, sanitation, and hygiene is silent on the several issues highlighted here, and the risks of COVID-19 transmission associated with shared water and sanitation facilities. This highlights the need to re-contextualize and adapt generic control measures to the African socioeconomic settings, cultures, and norms.

Weak and poorly enforced food hygiene, safety, and quality standards Food hygiene, quality, and safety standards are often non-existent or weak and poorly enforced in Africa (Boatemaa et al. 2019; Madaki and Bavorova 2019). Thus, unhygienic practices such as the use of bare hands, sneezing, blowing of one's nostrils, coughing, and spitting by infected persons during food processing, packaging, and serving may occur. These practices may lead to food cross-contamination with SARS-CoV-2. Comprehensive COVID-19 testing of workers in the food industry in Africa using polymerase chain reaction (PCR) test kits is time-consuming and expensive. The extent to which COVID-19 testing is conducted among workers in the food industry in most African countries is also unknown. Informal food vending in open food markets, streets, and even public transport such as buses and commuter omnibuses is common in Africa (Songe et al. 2017). Although no data exist showing COVID-19 contamination via such vended foods, vector-mediated contamination of food from open and street markets has been reported in some African countries (Phoku et al. 2016; Songe et al. 2017). Such practices increase the risk of food contamination with SARS-CoV2 via direct contact with infected surfaces, cross-contamination, and vectors such as houseflies. This is because such open and street food markets have no proper sanitation and handwashing facilities. Even in cases where shared public sanitation and hand-washing facilities exist, these facilities often lack sanitizers and soap required for effective disinfection.

In Africa, as in parts of Asia, several wild animals including ungulates, rodents, and birds are consumed as food in some communities (Fitzhenry et al. 2019; Martins and Shackleton 2019). The health risks posed by the consumption of wild animal products during COVID-19 outbreaks are still poorly understood. However, the transfer of zoonotic diseases from wild animals to livestock and then humans is well-documented (Mohamed 2020; Sichewo et al. 2020). To date, no studies exist investigating whether or not wild food animals in Africa are potential hosts of SARS-CoV-2. However, some studies suggest that SARS-CoV-1, the etiologic agent causing SARS1, was detected in palm civet food products (Ahmadiara 2020). Existing studies assessing the risks of COVID-19 transmission via food (e.g., Oakenfull and Wilson 2020) do not consider the exposure risks associated with the consumption of wild animal products such as bush-meat. This points to the need for caution in regions where consumption of wild food products is common. As a precaution, it is advisable to avoid consuming wild animal products during a COVID-19 outbreak. In cases where the consumption of such wild animal foods is unavoidable, precautions must be taken (e.g., proper cooking).

Unhygienic funeral practices Detailed guidelines and step-bystep procedures exist for the management and disposal of the remains of patients who have died from COVID-19 (Finegan et al. 2020, WHO 2020a). WHO (2020a) recommendations include the following, among others: (1) people preparing the body should not kiss the deceased, and should thoroughly wash hands with soap and water afterwards; (2) during body viewing, family members and friends should not touch or kiss the deceased, and physical distancing should be strictly applied; and (3) people with respiratory problems should not participate in body viewing or should at least wear a medical mask. Although these guidelines are comprehensive, their implementation presents several challenges, especially among poor communities. First, the recommendations assume that most of the COVID-19 deaths are diagnosed. However, due to poor health care coverage and low rates of COVID-19 testing in Africa, a significant number of deaths are likely to occur at home in remote rural areas without any COVID-19 diagnosis. Thus, it will be difficult to differentiate deaths due to COVID-19 from those attributable to other diseases. It is also unclear whether these recommendations have been widely disseminated at the country level, including remote rural areas. In most African countries, the living are closely linked to the dead through strong cultural and religious beliefs. Hence, regardless of one's health status and the cause of death, some burial and funeral rituals such as body viewing, kissing, and touching are common. Medical masks, laundry detergents, and chemical disinfectants such as chlorine cited in the WHO (2020a) recommendations are rarely affordable and available in typical rural settings in Africa. As mass fatalities due to COVID-19 occur, such elaborate procedures may be considered cumbersome. Instead, several risky practices, including burials within homesteads and in areas with shallow groundwater systems and even in wetlands, are likely to occur, thus increasing the risk of pollution of drinking water sources (Zume 2011). In summary, existing guidelines appear to have 
been developed for middle- to high-income communities, but are unlikely to be feasible among low-income and vulnerable communities in Africa, some of which cannot even afford basic food. In some countries, where PPE is now mandatory, the sharing of masks among the poor has been reported in an effort to avoid arrest. Hence, for such recommendations to be feasible, these material requirements should be provided either by government or aid agencies as part of COVID-19 control measures. Yet most African governments lack the resources and capacity to supply adequate PPE even to health care professionals.

Weak and under-funded health care and social security systems Weak and poorly funded health care and social security systems in Africa cannot cope with widespread outbreaks of infections such as COVID-19 (Ji et al. 2020). The lack of coping capacity in Africa is even evident in other diseases such as cholera and typhoid (Ahmed et al. 2011). The presence of weak social security systems coupled with low formal employment implies that mandatory social distancing via national lockdowns and self-quarantine significantly threaten household income, livelihoods, and food security of vulnerable communities. This may result in long-term adverse effects which may limit post-COVID-19 recovery.

Public medical diagnostic laboratories remain few and poorly equipped. Thus, Africa is currently experiencing a critical shortage of reverse transcriptase quantitative PCR (RTqPCR) testing kits required for reliable detection of SARSCoV-2, as such kits are expensive, and hence only a limited quantity exists in Africa (Shereen et al. 2020). Currently, most COVID-19 testing centers are confined to major urban centers, while such facilities are lacking in remote rural areas, where a significant proportion of the African population lives. Lacking PCR kits, defective and less reliable test kits have been used, often resulting in misleading results. African countries also lack reliable COVID-19 data on the number of people tested, confirmed cases, deaths, and recoveries. Thus, the extent and severity of COVID-19 transmission in most African countries is not known with certainty. Yet such data are critical for policy formulation, targeting the allocation of scarce resources, and even determining whether to upgrade or downgrade control measures such as national lockdowns.

Human disease and public health surveillance systems are often weak and even missing in most African countries (Tambo et al. 2014; Siedner et al. 2015). Yet such systems are critical for the early detection and control of infectious diseases including COVID-19. Lacking such surveillance systems, emergency response systems tend to be slow and poorly coordinated, thereby promoting rapid transmission of infectious diseases such as COVID-19. Due to the lack of resources and expertise, most African countries typically rely on donations from developed countries and the international community. Thus, any delays or lack of such donor or international support will delay implementation of control measures, allowing COVID-19 transmission to further expand.

Given the challenges highlighted, Africa, and particularly sub-Saharan Africa, has a high burden of human diseases including immune-suppressing HIV/AIDS, tuberculosis, malaria, Chikungunya virus, Ebola virus, and even waterborne diseases (e.g., cholera, typhoid) (Confraria and Wang 2020). Human disease vectors and pathogens proliferate and persist under the tropical conditions predominant in sub-Saharan Africa (Barclay 2008). Co-infections may synergistically interact with COVID-19, and predispose humans to adverse health risks and outcomes (Bengoechea and Bamford 2020; Lin et al. 2020). Therefore, in light of the high disease burden, synergistic interactions between COVID-19 and co-infections are expected to be more pronounced in Africa than in developing countries.

\section{Climatic and weather drivers of COVID-19 transmission}

Evidence shows that COVID-19 transmission dynamics are often correlated or coupled with climatic and weather drivers, with cold and dry conditions typical of winter seasons promoting the transmission and virulence of COVID-19 (Tosepu et al. 2020; Shi et al. 2020; Wu et al. 2020b). For example, the highest increase in daily infection rates in the predominantly temperate northern hemisphere in Western Europe coincided with dry and cold conditions (Miller et al. 2020). Modeling studies have also reported inverse relationships between various metrics of COVID-19 transmission (e.g., the basic reproductive number, $R$ ) and ambient temperature and relative humidity, although variations occur among locations (Wang et al. 2020). Laboratory studies also show that increasing temperature and humidity reduces the virulence of SARS viruses and other coronaviruses (Casanova et al. 2010; Miller et al. 2020), while air pollution increases virulence (Pansini and Fornacca 2020). These findings are consistent with the observations and anecdotal evidence showing that influenza outbreaks in sub-Saharan Africa and several other regions often occur in the winter season. However, a few studies have reported results showing no relationship between COVID-19 outbreaks, and weather and climatic drivers (Yao et al. 2020). For example, a regression analysis of COVID-19 data covering 224 cities in China revealed no significant relationship between COVID-19 transmission and increasing ultraviolet (UV) exposure, relative humidity, or maximum and minimum ambient temperatures (Yao et al. 2020). Other studies have shown that cases of certain coronavirusrelated diseases such as Middle East respiratory syndrome (MERS) continued to rise in the Middle East even when temperatures were as high as $45{ }^{\circ} \mathrm{C}$ (Alshukairi et al. 
2018). These mixed results suggest that climatic and weather controls on COVID-19 could vary among regions and countries, possibly due to varying control strategies and even transmission modes.

The bulk of sub-Saharan Africa experiences a predominantly tropical climate, and is currently experiencing a winter period characterized by dry and cold conditions. Hence, if the inverse relationship between temperature and humidity and COVID-19 transmission and virulence is valid in subSaharan Africa, then the following trends in COVID-19 outbreak are expected: (1) a spike in COVID-19 cases in the winter period between May and August this year, then followed by, (2) a drop in COVID-19 cases in the wet and warm summer season as rising temperatures and humidity suppress COVID-19 transmission and virulence. Recent observations seem to show that most countries in sub-Saharan Africa have experienced rapid increases in COVID-19 coinciding with the current winter period (Africa CDC 2020). However, at the country level, asynchronous COVID-19 outbreaks may also occur due to contrasting climates among countries, and because different countries implement mitigation measures to varying extents. Based on the anticipated weather controls on COVID-19 transmission, one would have expected countries in sub-Saharan Africa to tap into this knowledge to avoid the anticipated winter peak in COVID-19 infections by implementing strict social distancing measures during this period. Surprisingly, several countries in sub-Saharan Africa are planning to open learning institutions including schools, colleges, and universities at a time when peak COVID-19 outbreaks are anticipated. The reasons and the scientific evidence informing such decisions remain unclear, but the drive to relax or lift the lockdowns appear strong in several countries in subSaharan Africa (Vaughan 2020; https://www.bbc.com/news/ world-africa-52395976; https://www.afro.who.int/news/whourges-caution-countries-africa-ease-lockdowns). The implications of such decisions on the number of COVID-19 cases and deaths remain to be seen in most countries, but a surge in cases has been reported in some countries (http:// www.rfi.fr/en/africa/20200521-surge-in-cases-in-africa-afterlockdowns-lifted).

Currently, Africa lacks strong evidence relating COVID-19 outbreaks to climatic and weather drivers. However, the role of climatic controls and teleconnections in human disease outbreaks has been reported in Africa for several diseases including malaria and Chikungunya virus, among others (Anyamba et al. 2012; Caldwell et al. 2020). A question that arises in Africa is whether COVID-19 transmission dynamics will be coupled to climatic and weather controls, and result in contrasting transmission patterns in different climatic regions and countries. This is particularly interesting because the climatic and current weather conditions in African countries are quite heterogeneous. The dominant climates include wet and dry tropical, equatorial, tropical monsoon, semi-desert or semi- arid, desert or hyper-arid and arid, and subtropical highland climate (Pulsipher and Pulsipher 2008).

Climate or weather-based COVID-19 transmission models often assume that transmission occurs via respiratory droplets (Miller et al. 2020). As discussed later, novel COVID-19 transmission dynamics in Africa may occur through the fecal-oral route, food contamination, and vectors. Such novel COVID-19 transmission dynamics could present challenges to current modeling approaches based on conventional transmission modes. Thus, the relationships between COVID-19 transmission dynamics and climatic and weather controls in Africa require further investigation. Such research should also aim to identify the best predictors for estimating the transmission and virulence of COVID-19 and several co-infections in Africa. However, Africa faces several research challenges including the lack of reliable climatic and weather data, research funding, infrastructure, and even expertise (Biagini 2016).

\section{The critical role of the voice of the African research community}

The unique socioeconomic settings, risk factors, and the potential for novel COVID-19 transmission call for a rethink on how current generic recommendations can be adapted to suit the unique settings in Africa. In this regard, the scientific basis and validity of the key assumptions inherent in current generic recommendations may need to be validated against realities in Africa. In cases where such assumptions are considered invalid, such generic COVID-19 mitigation measures may need to be re-contextualized, adapted, and revised to better suit local realities. In some developed and low-income regions, this process has been evident to some extent, where the research community and several professional bodies have added their voice to the current discourse on COVID-19. For example, in the UK, the Food Standards Agency (FSA-UK) produced an opinion paper on the potential risks of COVID transmission via food (Oakenfull and Wilson 2020). In North America, the North American Alliance for the Study of Digestive Manifestations of COVID-19 (GICOVID19.org) launched a research network and a clinical database collating information characterizing the gastrointestinal and hepatic manifestations of COVID-19 from 30 centers in the USA and Canada (Aroniadis et al. 2020). Recently, the same network published a joint scoping review on the current knowledge and research needs on manifestations of COVID-19 in the human digestive system (Aroniadis et al. 2020). Several other expert opinions exist in other countries and regions, including low-income ones such as Latin America, the Caribbean region (Miller et al. 2020), and Asia (Fiesco-Sepúlveda and SerranoBermúdez 2020; Kakimoto et al. 2020; Pung et al. 2020), among others.

Despite the rising number of COVID-19 cases in Africa, such learned opinions from the African research community 
are largely missing. Only a few exceptions exist, focusing on: (1) the need for collective action to combat COVID-19 in Africa (Nkengasong and Mankoula 2020), and (2) a few others on the occurrence of COVID-19, and the preparedness, and vulnerability of Africa (Gilbert et al. 2020; Kapata et al. 2020; Martinez-Alvarez et al. 2020). Now that the COVID-19 wave has hit Africa, one would have expected an influx of scientific expert opinions, viewpoints, commentaries, and even scoping and horizon scanning reviews from the African research community. Horizon scanning reviews provide foresight on emerging issues, and highlight critical issues to be addressed on a subject, even in cases where experimental data are not available (Cuhls 2015). It is in this regard that the voice of the African research community with intimate knowledge of the African sociocultural norms and practices should be raised high in the scientific discourse on COVID-19 in Africa. This is particularly true given that Africa, like other regions, is home to several universities, research institutes, and learned professional bodies spanning public health, the food industry, water and sanitation, and social and behavioral sciences, among others. Surprisingly, barring the current perspective, this process has been largely missing, and the voice of the African research community on the issues highlighted here has been conspicuous by its absence.

The reasons for the subdued voice of the African research community are unclear, but may include the following: first, lack of expertise in infectious diseases of the nature and magnitude of COVID-19. The fact that several African countries rely on external experts for other infectious diseases such as Ebola virus (Gee and Skovdal 2017), and even waterborne diseases such as cholera (Ahmed et al. 2011), seems to support this notion. Second, due to poor research funding and infrastructure, barring South Africa and some countries in North Africa, Africa has one of the weakest research systems in the world, and several studies have highlighted this limitation (Whitworth et al. 2008; Chu et al. 2014). Thus, a weak scientific evidence base may exist on infectious diseases such as COVID-19 to warrant authoritative expert opinions or viewpoints. Finally, generic control measures from authoritative global agencies such as WHO $(2020 \mathrm{a}, \mathrm{b}, \mathrm{c})$, and national health agencies from developed countries such as the Centers for Disease Control and Prevention (CDC) in the USA (CDC 2020) and the National Health Service (NHS) in the UK (https://www.nhs.uk/conditions/coronavirus-covid19/), among others, may be considered as "global best practices." Given the advancement of scientific research systems in such developed countries, the African scientific community could be of the view that such global best practices are beyond reproach. Others may also argue that Africa, including its research community, is now overwhelmed by COVID-19, and hence any attempts or suggestions to change the mitigation strategy in the middle of the crisis may confuse the public and cause loss of confidence, resulting in disastrous health outcomes. However, the unique risk factors and challenges, as well as the potential for novel COVID-19 transmission, point to the need for revisions of current guidelines. Clearly, the opinions of the African scientific community should guide that process. Thus, scope exists for the African voice to be heard with respect to COVID-19 in Africa.

\section{Novel COVID-19 transmission dynamics and hotspots}

\section{Transmission modes}

As reported in the scientific literature, the conventional transmission of SARS-CoV-2 occurs predominantly via the respiratory route and direct contact (WHO 2020b, c). This understanding is also consistent with the positions of expert global health organizations such as WHO and national health agencies such as NHS (UK) and CDC (USA). This transmission mode is based on the fact that until recently, SARS-CoV-2 has been detected in swab samples from the human respiratory system. However, recent studies detecting SARS-CoV-2 RNA in the human gastrointestinal system, feces, and wastewater point to other novel transmission mechanisms. These novel transmission modes, including the fecal-oral route, cross-contaminated food, and vector-mediated transmission, have attracted significant research attention (Goh et al. 2020; $\mathrm{Gu}$ et al. 2020; Heller et al. 2020; Hindson 2020). Here, the current evidence supporting each transmission mode is summarized in the African context.

Fecal-oral COVID-19 transmission The three key lines of evidence supporting the potential for fecal-oral transmission of COVID-19 are summarized as follows.

\section{(1) SARS-CoV-2 in the human gut and feces}

The human gastrointestinal tract is a hotspot reservoir for SARS-CoV-2, which is in turn shed via feces from both symptomatic and asymptomatic infected persons (He et al. 2020; Pan et al. 2020; Wu et al. 2020a; Young et al. 2020). SARS$\mathrm{CoV}-2$ shedding periods as long as 33 days may occur in some infected persons even after SARS-CoV-2 tests on respiratory samples are negative (Wu et al. 2020a). Thus, SARS-CoV-2 shed via feces are potentially released into the environment via open defecation, and through wastewater and effluent discharge from on-site sanitation systems (e.g., pit latrines, septic tanks) and municipal sewer systems.

\section{(2) Wastewater-based epidemiology}

Wastewater-based epidemiology (WBE) relies on the surveillance of pathogens and their proxies (e.g., SARS-CoV-2 RNA titers) in raw wastewater systems to gain insight into the 
nature and magnitude of human infections (e.g., COVID-19) in a catchment (Ahmed et al. 2020; Mallapaty 2020). Recent studies applying WBE have detected SARS-CoV-2 RNA in raw wastewater in Australia (Ahmed et al. 2020), France (Wurtzer et al. 2020), Italy (La Rosa et al. 2020), the Netherlands (Medema et al. 2020), Spain (Randazzo et al. 2020), and China (Zhang et al. 2020). For example, Ahmed et al. (2020) used WBE combined with Monte Carlo simulation modeling and estimated that, based on the SARS-CoV-2 RNA titers, a median of 171 to 1090 COVID-19-infected persons were in the studied catchment. In China, SARSCoV-2 RNA was detected in medical wastewater from septic tanks even after disinfection with sodium hypochlorite at a dose of $800 \mathrm{~g} / \mathrm{m}^{3}$ (Zhang et al. 2020). Thus, raw wastewater systems may harbor SARS-CoV-2, which may subsequently undergo dissemination into drinking water and food sources (e.g., aquatic foods). This recent evidence seems to contradict and supersede the earlier World Health Organization position that "no studies exist on COVID-19 virus in drinking water and sewage" (WHO 2020e). This contradiction can be attributed to the fact that research on COVID-19 is rapidly evolving, and hence WHO updates may lag behind recent scientific evidence.

\section{(3) SARS-CoV-2 shell structure and modeling evidence}

Goh and colleagues investigated shell disorder of SARSCoV-2 and other coronaviruses using molecular methods and artificial intelligence to understand their persistence, transmission routes, and virulence (Goh et al. 2020). Compared to other coronaviruses, SARS-CoV-2 is unique in that it has a rigid or hard shell that confers environmental persistence outside the human body and body fluids (Goh et al. 2020). For example, evidence shows that SARS-CoV-2 may persist on surfaces for up to 6 to 9 days, which increases the chance for transmission via the various modes (Van Doremalen et al. 2020; Wu et al. 2020a). Moreover, among the studied coronaviruses, SARS-CoV-2 had the lowest shell disorder as evidenced by its low percentage of intrinsic disorder (PID) (Goh et al. 2020). The low PID of SARS-CoV-2 points to its moderate potential for transmission via both fecal-oral and respiratory routes. Thus, according to Goh and coworkers (Goh et al. 2020), a combination of high stability conferred by a rigid or hard shell and low shell disorder give further credence to potential fecal-oral transmission. This notion is additionally supported by independent modeling studies showing that a COVID-19 transmission model accounting only for respiratory and direct contact transmission failed to explain the patterns of the Wuhan COVID-19 outbreak (Danchin et al. 2020). A similar model accounting for the multiple transmission modes, including the fecal-oral route, gave a better fit between the model results and the observed data (Danchin et al. 2020). Taken together, these findings, when interpreted with the risk factors and challenges, indicate that SARS-CoV-2 transmission via the fecal-oral route could play a critical role in the proliferation of COVID-19 in Africa and other low-income regions.

Transmission along the farm-to-fork food chain The food chain includes production, harvesting, processing, logistics (storage and transport), preparation, and serving (Oakenfull and Wilson 2020). Along this chain, SARS-CoV-2 contamination may occur via two sources: (1) contaminated soils (e.g., sludge-amended soils) and irrigation water (e.g., wastewater), and (2) infected food handlers. A few review studies have investigated the potential risk of COVID-19 transmission via the food chain (Oakenfull and Wilson 2020; Li et al. 2020; Shariatifar and Molaee-aghaee 2019). For example, in the UK, the Food Safety Agency (FSA-UK) assessed the risk of COVID-19 transmission via two routes, specifically consumption of: (1) foodstuffs such as eggs, milk, meat, dairy, and blood products from infected food animals and animal food products, and (2) cross-contaminated foodstuffs via (i) contaminated animal products, (ii) non-animal foods, (iii) food contact materials, (iv) preparation surfaces, and (v) infected persons involved in food preparation (Oakenfull and Wilson 2020). FSA-UK concluded that the overall risk for COVID-19 transmission was negligible for contaminated foodstuffs of animal origin, while that for the crosscontamination of foodstuffs was very low (Oakenfull and Wilson 2020). In Singapore, Li et al. (2020) also concluded that the risk of COVID-19 transmission via food was low. These studies are based on the assumption that proper hygiene, quality control, and safety procedures are strictly followed at each step in the food chain. However, this is often not the case in Africa, where food hygiene, quality, and safety procedures are often non-existent or weak and poorly enforced.

Given the lack of regular surveillance to determine infected persons in Africa, SARS-CoV-2 may be transmitted to food via sneezing, coughing, and handling during food processing, packaging, and serving. In some African communities, familial dining practices commonly involve family members sharing food from the same plate. In such settings, familial fecaloral transmission of COVID-19 may occur via contaminated hands. Transmission via shared food has been reported in some studies conducted in Asia (e.g., Pung et al. 2020). This is contrary to dining practices in developed countries, where each person eats from his/her own plate, thereby minimizing the risk of cross-contamination and familial transmission. These aspects, and vector-mediated contamination of food, are not addressed in existing risk assessment studies conducted in developed countries (e.g., Oakenfull and Wilson 2020). Hence, two points are noteworthy: (1) conclusions based on studies conducted in developed countries cannot be directly extrapolated to Africa without considering the unique African 
context and risk factors, and (2) independent risk assessments for COVID-19 transmission via cross-contaminated food are needed in Africa, taking into account its unique settings.

Vector-mediated transmission In principle, two preconditions should exist for vector-mediated transmission of SARS-CoV2 from environmental sources to the human receptor. First, viable and virulent SARS-CoV-2 should exist in environmental media accessible to the vector (e.g., household flies, cockroaches, rodents). In this case, fecal matter from on-site sanitation systems, open defecation, and wastewater may act as SARS-CoV-2 reservoirs for vector-mediated food contamination. Second, such environmental media must attract vectors, which then act as a host and/or come into direct contact with the SARS-CoV-2, and subsequently transmit it to humans directly or via intermediate media such as food. The latter scenario is most likely, where vectors such as household flies, cockroaches, and rodents are attracted to and frequent fecalcontaminated sources and then transfer the SARS-CoV-2 to human food. This mechanism was proposed in earlier studies focusing on the fecal-oral transmission hypothesis (Bonato et al. 2020; Heller et al. 2020; Yeo et al. 2020).

Direct evidence documenting COVID-19 transmission via vectors is still limited. In addition, studies investigating potential human health risks via food contamination in developed countries (Li et al. 2020; Oakenfull and Wilson 2020) overlooked vector-mediated transmission. This is obviously because such a transmission mechanism is regarded as highly unlikely in developed countries due to strict food hygiene, quality, and safety standards. Evidence drawn from Africa and elsewhere in low-income regions shows that several vectors, including rodents and houseflies, that are attracted to fecal matter, on-site sanitation systems, and even human cadavers are also frequently found in households (Songe et al. 2017; Akter et al. 2020; Al-Khalifa et al. 2020). One study conducted in Zambia showed that houseflies which infested fish in open food markets acted as vectors for the transmission of antibiotic-resistant pathogenic Salmonella and Escherichia coli (Songe et al. 2017). Therefore, in light of the poor food hygiene and safety standards in Africa, vector-mediated COVID-19 transmission via the fecal matter-food-human pathway cannot be ruled out. Hence, this transmission mode warrants further research in Africa, focusing on food in households, open food markets, and street-vended foods, especially at the point of consumption.

\section{COVID-19 transmission hotspots}

Considering the potential multiple transmission modes of COVID-19 highlighted here, community settings where overcrowding is common, and shared water and sanitation facilities constitute potential COVID-19 transmission hotspots. In infectious disease epidemiology, hotspots are spatial or community clusters with unusually high disease burden or transmission efficiency relative to other environments (Lessler et al. 2017). Thus, potential COVID-19 hotspots include: (1) prisons and correctional services facilities, (2) overcrowded quarantine centers and health care facilities, (3) informal settlements such as slums, squatter camps, and refugee camps, and (4) even learning institutions such as schools, colleges and universities. In such settings, community or shared water and sanitation facilities are often used, and social distancing could be problematic due to overcrowding. With respect to shared water facilities, women and girls are particularly vulnerable due to their roles in household water provision, as they frequently spend prolonged periods in long queues at shared water points. Women and girls are also often responsible for cleaning of sanitation facilities, risking exposure to COVID-19 via aerosols and fomites from shared sanitation facilities.

Prison and correctional facilities are potential COVID-19 transmission hotspots because they are often overcrowded and have poor water and sanitation facilities (UN 2020). In some prisons and correctional facilities, a typical cell shared among several inmates consists of a toilet-cum-bathroom and bedroom combined in one unit. Due to excessive overcrowding, high incidences of infectious diseases such as tuberculosis have been reported in several prisons and correctional facilities in Africa (O'Grady et al. 2011; Jaquet et al. 2016). Moreover, as the number of COVID-19 cases, returnees, and deportees increases, overcrowding in quarantine centers is likely to occur. As in prisons and correctional services facilities, shared water and sanitation facilities are common in quarantine centers. Media reports show that high rates of COVID19 cases have been reported in prisons and quarantine centers in Africa and other low-income regions due to overcrowding and unhygienic conditions, pointing to the possibility of community transmission (Schlein 2020; UN 2020). Yet most people in prisons and correctional services, slums, squatter camps, and refugee settlements are vulnerable, because they have no reliable source of income or livelihood. Such vulnerable people are often excluded in COVID-19 programs such as diagnostic testing, formulation of policies, and control strategies, and even allocation of scarce resources such as PPE. Hence, government and humanitarian agencies should ensure that such vulnerable people in these and other settings are not excluded in the fight against COVID-19. Current WHO (2020b, c) guidelines and even national guidelines and control measures on COVID-19 often exclude these potential transmission hotspots and vulnerable groups.

\section{Novel COVID-19 transmission calls for additional safeguards}

The unique risk factors, challenges, and potential for novel transmission, coupled with the infectious nature of COVID19, are herein termed "dangerous liaisons." These dangerous 
liaisons point to potential complex COVID-19 transmission dynamics, resulting in potentially more adverse human health outcomes in Africa relative to developed countries. Yet, currently, incontrovertible scientific evidence linking the novel transmission modes to COVID-19 outbreaks is still lacking. However, the lack of evidence attributable to absence of studies on the subject should not be misinterpreted as absence of human health risks. In this regard, based on the lines of evidence summarized here, COVID-19 transmission via the fecal-oral route, contaminated food, and vectors cannot be ruled out in Africa. Thus, given the severity and adverse human health outcomes associated with COVID-19, Africa, and possibly other low-income regions, may need to assume the "worst-case scenario" and adopt the precautionary principle. In simple terms, the precautionary principle implies that in the absence of a comprehensive understanding of the transmission dynamics of COVID-19, Africa should assume the worst-case scenario and take appropriate precautions. These precautions entail adapting, re-contextualizing, and revising existing generic control measures as well as implementing additional safeguards to suit African settings. Specifically, the following recommendations are proposed:

\section{(1) Reliable clean drinking water provision}

The provision of reliable and clean drinking water where available, and/or treating drinking water via boiling and disinfection using chlorination, should be an integral part of the COVID-19 control measures (WHO 2020e). Water disinfection reduces the risk of fecal-oral transmission, because SARS-CoV-2 is sensitive to temperatures above $65^{\circ} \mathrm{C}$ and biocidal agents such as chlorine and hypochlorite. Reliable water supplies also reduce community transmission via overcrowding at community shared water points. Clean water provision also reduces the risk of waterborne co-infections such as cholera and typhoid, and enables communities to adhere to social distancing measures such as lockdowns.

\section{(2) Improved sanitation and hygiene practices}

Proper sanitation should be urgently provided in areas where it is currently lacking. Particular attention should be paid to informal settlements, slums, squatter camps, and refugee camps. This is critical to avoid open defecation and subsequent potential transmission of COVID-19 via vectors. In the case of shared sanitation facilities, the availability of adequate facilities must be ensured to avoid overcrowding. The cleaning of such shared sanitation facilities should not be the sole responsibility of women and girls. Rather, the responsibility should be shared fairly, between women and girls on the one hand, and their male counterparts on the other hand.

\section{(3) Food hygiene, quality control, and safety}

Proper food hygiene, handling, and safety procedures including washing and proper cooking are critical to reducing the potential risk of COVID-19 transmission via contaminated food along the farm-to-fork chain. Unhygienic practices such as informal vending of food in open markets and streets, and public transport should be prohibited. Human food surveillance systems should be strengthened to ensure that foods from sick animals and potentially contaminated sources do not enter the human food chain. Proper cooking of food is critical, since SARS-CoV-2 is sensitive to temperature. Moreover, foods from potentially contaminated sources such wastewater irrigation and wastewater-based aquacultural systems should be avoided during a COVID-19 outbreak.

\section{(4) Protecting vulnerable people in COVID-19 transmission hotspots}

Women and girls using shared water and sanitation facilities, prisoners and workers in the prison and correctional facilities, and returnees, deportees, and workers in quarantine centers constitute vulnerable groups associated with COVID-19 transmission hotspots. To minimize the risk of COVID-19 transmission, the following control measures are recommended:

(i) Hand-washing facilities, including sanitizers, are needed at shared water and sanitation facilities such as boreholes, wells, and toilets. Clear signage informing the public of the need to wash hands before and after using such facilities, and even to clean water abstraction devices (e.g., handles), should be included at these shared facilities.

(ii) Overcrowding should be avoided in prison and correctional, and quarantine facilities during COVID-19 outbreaks. In both prison and correctional, and quarantine facilities, inmates should be screened before being accommodated in such facilities. Moreover regular and frequent COVID-19 screening will be required to ensure that infected people are accommodated separately from the non-infected ones.

\section{(5) Revising current guidelines and raising awareness}

The highlighted additional safeguards may necessitate the revision and adaptation of current guidelines to reflect the unique African settings. Consequently, such additional safeguards and revisions will need to be systematically communicated to the various stakeholders without causing panic and confusion. This requires raising public awareness on the additional safeguards through well-structured educational campaigns, pamphlets, and media updates. Besides mitigating COVID-19, the proposed additional safeguards are critical for safeguarding human health against other human coinfections in Africa including waterborne diseases. However, 
it remains unclear whether African governments and international and national agencies are prepared to embrace these realties and adjust and revise the current mitigation strategies accordingly. This is because Africa is now in the midst of a COVID-19 crisis, and some may argue that a shift in the control strategy could cause loss of confidence and create confusion among stakeholders.

\section{Concluding remarks}

The current perspective highlights how the interactions of COVID-19 transmission and infectivity, and the inherent risk factors and challenges in Africa, could culminate in complex transmission dynamics and adverse human health outcomes. It was demonstrated that while the recommendations of global health institutions such as WHO are premised on respiratory and direct contact transmission modes, novel transmission may also play a key role in COVID-19 transmission in Africa. Thus, COVID-19 transmission via the fecal-oral route, vectors, and food contamination in the farm-to-fork food chain cannot be ruled out. The potential for fecal-oral, vector-mediated, and food transmission modes adds another layer of complexity to COVID-19 transmission and control in Africa. The reasons for this were highlighted, and include: (1) poor water and sanitation infrastructure, (2) poor hygiene practices that increase the risk of human exposure, and (3) poor food hygiene, quality, and safety procedures in the food chain. Thus, unless additional safeguards are implemented, COVID-19 infection and mortality rates in Africa could be higher than current predictions premised solely on respiratory and direct contact transmission. Therefore, as a precaution to reduce the risk of novel transmission and to protect human health, the following additional safeguards and recommendations were proposed: (1) strengthen the water, sanitation, and hygiene (WASH) component through clean water provision and proper sanitation to avoid open defecation; (2) engage in good food hygiene and safety practices along the farm-to-fork food chain, including washing and proper cooking of food, and avoid or ban open market- and street-vended foods; (3) increase public awareness of the need for the additional safeguards that are unique to Africa; and (4) pay particular attention to COVID-19 transmission hotspots and vulnerable people such as prisoners, women, children, and those in quarantine centers, slums, squatter camps, and refugee camps. The proposed safeguards are not meant to replace current mitigation measures, but rather are additional and complementary to current measures based on the use of PPE, social distancing, and frequent hand washing.

Acknowledgements I thank the two anonymous reviewers for their comments that improved both the quality and presentation of the manuscript.
Disclaimer This manuscript does not contain any original data or experimental results. The views and opinions expressed herein are solely those of the author in his individual capacity. The content of the manuscript does not in any way represent the views, decisions, or opinions of the author's affiliate institution.

Funding This research received no funding from public, private or nonprofit organizations. Therefore, the author declares no conflict of interest, financially or otherwise, which could have influenced his interpretations and opinions.

\section{Compliance with ethical standards}

Ethical approval The current perspective is based on analysis and interpretation of existing evidence. Thus, no approvals are required to conduct and publish such research.

Informed consent The current perspective is based on analysis and interpretation of existing evidence. No informed consent approvals are required for such a study.

\section{References}

Abuya T, Austrian K, Isaac A, Kangwana B, Mbushi F, Muluve E, Mwanga D, Ngo T, Nzioki M, Ochako R, Pinchoff J, Tidwell B, White C (2020) COVID-19-related knowledge, attitudes, and practices in urban slums in Nairobi, Kenya: study description. Population Council, Nairobi https://knowledgecommons. popcouncil.org $/ \mathrm{cgi} / \mathrm{viewcontent}$.cgi article $=1998 \&$ context $=$ departments_sbsr-pgy. Accessed 10 June 2020

Adepoju A (2005) Review of research and data on human trafficking in sub-Saharan Africa. Int Migr 43(1-2):75-98

Africa CDC (Centre for Disease Control and Prevention) (2020) Coronavirus Disease 2019 (COVID-19): Latest updates on the COVID-19 crisis from Africa CDC. https://africacdc.org/covid19/. Accessed 4 June 2020

Ahmadiara E (2020) Possibility of Faecal-Oral transmission of novel coronavirus (SARS-CoV-2) via consumption of contaminated foods of animal origin: a hypothesis. J Food Qual Hazards Control 7:2-3. https://doi.org/10.18502/jfqhc.7.1.2445

Ahmed S, Bardhan PK, Iqbal A, Mazumder RN, Khan AI, Islam MS, Siddique AK, Cravioto A (2011) The 2008 cholera epidemic in Zimbabwe: experience of the icddr, $\mathrm{b}$ team in the field. $\mathrm{J}$ Health Popul Nutr 29(5):541

Ahmed W, Angel N, Edson J, Bibby K, Bivins A, O’Brien JW, Choi PM, Kitajima M, Simpson SL, Li J, Tscharke B, Verhagen R, Smith WJM, Zaugg J, Dierens L, Hugenholtz P, Thomas KV, Mueller JF (2020) First confirmed detection of SARS-CoV-2 in untreated wastewater in Australia: a proof of concept for the wastewater surveillance of COVID-19 in the community. Sci Total Environ. https://doi.org/10.1016/j.scitotenv.2020.138764

Akter S, Sabuj AAM, Haque ZF, Rahman MT, Kafi MA, Saha S (2020) Detection of antibiotic-resistant bacteria and their resistance genes from houseflies. Vet World 13(2):266-274. https://doi.org/10. 14202/vetworld.2020.266-274

Ali M, Wang W, Chaudhry N, Geng Y (2017) Hospital waste management in developing countries: a mini review. Waste Manag Res 35(6):581-592

Al-Khalifa MS, Mashaly AM, Al-Qahtni AH (2020) Insect species colonized indoor and outdoor human corpses in Riyadh, Saudi Arabia. J King Saud Univ Sci 32(3):1812-1817. https://doi.org/10.1016/j. jksus.2020.01.034 
Alshukairi AN, Zheng J, Zhao J, Nehdi A, Baharoon SA, Layqah L, Bokhari A, Al Johani SM, Samman N, Boudjelal M, Ten Eyck P, Al-Mozaini MA, Zhao J, Perlman S, Alagaili AN (2018) High prevalence of MERS-CoV infection in camel workers in Saudi Arabia. mBio 4(5):e01985-18. https://doi.org/10.1128/mBio.01985-18

Anyamba A, Linthicum KJ, Small JL, Collins KM, Tucker CJ, Pak EW, Britch SC, Eastman JR, Pinzon JE, Russell KL (2012) Climate teleconnections and recent patterns of human and animal disease outbreaks. PLoS Negl Trop Dis 6(1):e1465. https://doi.org/10. 1371/journal.pntd.0001465

Aroniadis OC, DiMaio CJ, Dixon RE, Elmunzer BJ, Kolb JM, Mendelsohn R, Singal AG, Ordiah CO, Rockey DC, Spitzer RL, Tierney WM (2020) Current knowledge and research priorities in the digestive manifestations of COVID-19. Clin Gastroenterol Hepatol 8:1682-1684. https://doi.org/10.1016/j.cgh.2020.04.039

Barclay E (2008) Predicting the next pandemic. Lancet 372(9643):10251026

Bengoechea JA, Bamford CG (2020) SARS-CoV-2, bacterial co-infections, and AMR: the deadly trio in COVID-19?. EMBO Mol Med 12:e12560. https://doi.org/10.15252/emmm.202012560

Beukes LS, King TL, Schmidt S (2017) Assessment of pit latrines in a peri-urban community in KwaZulu-Natal (South Africa) as a source of antibiotic resistant E. coli strains. Int J Hyg Environ Health 220(8):1279-1284

Biagini B (2016) Sub-Saharan Africa needs next-generation weather and climate services. https:/www.undp.org/content/undp/en/home/ blog/2016/11/9/Sub-Saharan-Africa-needs-next-generationweather-and-climate-services.html. Accessed 30 May 2020

Boatemaa S, Barney M, Drimie S, Harper J, Korsten L, Pereira L (2019) Awakening from the listeriosis crisis: food safety challenges, practices and governance in the food retail sector in South Africa. Food Control 104:333-342

Bonato G, Dioscoridi L, Mutignani M (2020) Faecal-oral transmission of SARS-COV-2: practical implications. Gastroenterology. https://doi. org/10.1053/j.gastro.2020.03.066

Buheji M, da Costa CK, Beka G, Mavric B, de Souza YL, da Costa Silva SS, Hanafi M, Yein TC (2020) The extent of covid-19 pandemic socio-economic impact on global poverty. A global integrative multidisciplinary review. Am J Econ 10(4):213-224

Caldwell JM, LaBeaud AD, Lambin EF, Stewart-Ibarra AM, Ndenga BA, Mutuku FM, Krystosik AR, Ayala EB, Anyamba A, BorborCordova MJ, Damoah R (2020) Climate explains geographic and temporal variation in mosquito-borne disease dynamics on two continents. bioRxiv. https://doi.org/10.1101/2020.02.07.938720

Caruso BA, Freeman MC (2020) Shared sanitation and the spread of COVID-19: risks and next steps. Lancet Planet Health 4(5):e173

Casanova LM, Jeon S, Rutala WA, Weber DJ, Sobsey MD (2010) Effects of air temperature and relative humidity on coronavirus survival on surfaces. Appl Environ Microbiol 76(9):2712-2717

CDC (Centre for Disease Control, USA) (2020) COVID, C. and team, R. severe outcomes among patients with coronavirus disease 2019 (COVID-19)-United States, February 12-march 16, 2020. MMWR Morb Mortal Wkly Rep 69(12):343-346

Chersich MF, Gray G, Fairlie L, Eichbaum Q, Mayhew S, Allwood B, English R, Scorgie F, Luchters S, Simpson G, Haghighi MM (2020) COVID-19 in Africa: care and protection for frontline healthcare workers. Glob Health 16:1-6

Chu K, Jayaraman S, Kyamanywa P, Ntakiyiruta G (2014) Building research capacity in Africa: equity and global health collaborations. PLoS Med 11(3)

Confraria H, Wang L (2020) Medical research versus disease burden in Africa. Res Policy 49(3):103916

Costa K (2020) The cause of panic at the outbreak of COVID-19 in South Africa-a comparative analysis with similar outbreak in China and New York. Available at SSRN 3613597
Cuhls K (2015) Models of horizon scanning: how to integrate horizon scanning into European research and innovation policies, Report for the European Commission by Fraunhofer ISI. TNO and VTT, Karlsruhe

Danchin A, Ng TWP, Turinici G (2020) A new transmission route for the propagation of the SARS-CoV-2 coronavirus. MedRxiv preprint. Posted on February 18, 2020. https://doi.org/10.1101/2020.02.14. 20022939

Durand-Lasserve A (2006) Informal settlements and the millennium development goals: global policy debates on property ownership and security of tenure. Glob Urban Dev 2(1):1-15

Fiesco-Sepúlveda KY, Serrano-Bermúdez LM (2020) Contributions of Latin American researchers in the understanding of the novel coronavirus outbreak: a literature review. PeerJ 8:e9332

Finegan O, Fonseca S, Pierre GH, Mendez MDM, Gonzalez JR, TidballBinz M, Winter KA (2020) ICRC advisory group on the management of COVID-19 related fatalities. For Sci Int Synergy 2:129-137

Fitzhenry LB, Cawthorn DM, Muchenje V, Bureš D, Kotrba R, Hoffman LC (2019) Carcass composition and yields of wild fallow deer (Dama dama) in South Africa. Afr J Wildl Res 49(1)

Fuente D, Allaire M, Jeuland M, Whittington D (2020) Forecasts of mortality and economic losses from poor water and sanitation in sub-Saharan Africa. PLoS One 15(3):e0227611

Gee S, Skovdal M (2017) Navigating 'riskscapes': the experiences of international health care workers responding to the Ebola outbreak in West Africa. Health Place 45:173-180

Gilbert M, Pullano G, Pinotti F, Valdano E, Poletto C, Boëlle PY, d'Ortenzio E, Yazdanpanah Y, Eholie SP, Altmann M, Gutierrez B (2020) Preparedness and vulnerability of African countries against importations of COVID-19: a modelling study. Lancet 395(10227): 871-877

Goh GKM, Dunker AK, Foster JA, Uversky VN (2020) Shell disorder analysis predicts greater resilience of the SARS-CoV-2 (COVID19) outside the body and in body fluids. Microb Pathog 144: 104177. https://doi.org/10.1016/j.micpath.2020.104177

Gu J, Han B, Wang J (2020) COVID-19: gastrointestinal manifestations and potential fecal-oral transmission. Gastroenterology

Gwenzi W (2020a) Autopsy, thanatopraxy, cemeteries and crematoria as hotspots of toxic organic contaminants in the funeral industry continuum: a hidden health risk or myth? Sci Total Environ 753: 141819. https://doi.org/10.1016/j.scitotenv.2020.141819

Gwenzi W (2020b) Leaving no stone unturned in light of the COVID-19 faecal-oral hypothesis? A water, sanitation and hygiene (WASH) perspective targeting low-income countries. Sci Total Environ 753:141751. https://doi.org/10.1016/j.scitotenv.2020.141751

Gwenzi W (2020c) The 'Thanato-resistome' - the funeral industry as a potential reservoir of antibiotic resistance: early insights and perspectives. Sci Total Environ 141120. https://doi.org/10.1016/j. scitotenv.2020.141120

Gwenzi W, Sanganyado E (2019) Recurrent cholera outbreaks in SubSaharan Africa: moving beyond epidemiology to understand the environmental reservoirs and drivers. Challenges 10(1):1. https:// doi.org/10.3390/challe10010001

He X, Lau EHY, Wu P, Deng X, Wang J, Hao X, Lau YC, Wong JY, Guan Y, Tan X, Mo X, Chen Y, Liao B, Chen W, Hu F, Zhang Q, Zhong M, Wu Y, Zhao L, Zhang F, Cowling BJ, Li F, Leung GM (2020) Temporal dynamics in viral shedding and transmissibility of COVID-19. Nat Med

Heller L, Mota CR, Greco DB (2020) COVID-19 faecal-oral transmission: are we asking the right questions? Sci Total Environ 729: 138919. https://doi.org/10.1016/j.scitotenv.2020.138919

Hindson J (2020) COVID-19: faecal-oral transmission? Nat Rev Gastroenterol Hepatol 17(5):259-259

Jaquet A, Wandeler G, Tine J, Dagnra CA, Attia A, Patassi A, Ndiaye A, de Ledinghen V, Ekouevi DK, Seydi M, Dabis F (2016) HIV 
infection, viral hepatitis and liver fibrosis among prison inmates in West Africa. BMC Infect Dis 16(1):249

Ji Y, Ma Z, Peppelenbosch MP, Pan Q (2020) Potential association between COVID-19 mortality and health-care resource availability. Lancet Glob Health 8(4):e480

Jones JL (2019) Headless queues: disorder and disorientation in a Zimbabwean market, 2007-2008. HAU: J Ethnogr Theory 9(3): $545-564$

Kakimoto K, Kamiya H, Yamagishi T, Matsui T, Suzuki M,Wakita T (2020) Initial investigation of transmission of COVID-19 among crew members during quarantine of a cruise ship-Yokohama, Japan, February 2020. MMWR Morb Mortal Wkly Rep 69. Available at: https://stacks.cdc.gov/view/cdc/85919. Accessed 30 May 2020

Kapata N, Ihekweazu C, Ntoumi F, Raji T, Chanda-Kapata P, Mwaba P, Mukonka V, Bates M, Tembo J, Corman V, Mfinanga S (2020) Is Africa prepared for tackling the COVID-19 (SARS-CoV-2) epidemic. Lessons from past outbreaks, ongoing pan-African public health efforts, and implications for the future. Int J Infect Dis 93:233-236

Khemani S (2020) An opportunity to build legitimacy and trust in public institutions in the time of COVID-19. Research and Policy Briefs 32. Available at: https://openknowledge.worldbank.org/bitstream/ handle/10986/33715/An-Opportunity-to-Build-Legitimacy-andTrust-in-Public-Institutions-in-the-Time-of-COVID-19.pdf? sequence $=1$. Accessed 24 May 2020

La Rosa G, Iaconelli M, Mancini P, Ferraro GB, Veneri C, Bonadonna L, Lucentini L, Suffredini E (2020) First detection of SARS-CoV-2 in untreated wastewaters in Italy. Sci Total Environ 736:139652. https://doi.org/10.1016/j.scitotenv.2020.139652

Lessler J, Azman AS, McKay HS, Moore S (2017) What is a hotspot anyway? Am J Trop Med Hyg 96(6):1270-1273

Li P, Fu JB, Li KF, Chen Y, Wang HL, Liu LJ, Liu JN, Zhang YL, Liu SL, Tang A, Tong ZD (2020) Transmission of COVID-19 in the terminal stage of incubation period: a familial cluster. Int J Infect Dis

Lin D, Liu L, Zhang M, Hu Y, Yang Q, Guo J, Guo Y, Dai Y, Xu Y, Cai Y, Chen X (2020) Co-infections of SARS-CoV-2 with multiple common respiratory pathogens in infected patients. Sci China Life Sci: $1-4$

Lodder W, de Roda Husman AM (2020) SARS-CoV-2 in wastewater: potential health risk, but also data source. Lancet Gastroenterol Hepatol 5(6):533-534. https://doi.org/10.1016/S2468-1253(20) 30087-X

Madaki MY, Bavorova M (2019) Food safety knowledge of food vendors of higher educational institutions in Bauchi state, Nigeria. Food Control 106:106703

Mahler DG, Lakner C, Aguilar RC, Wu H (2020) The impact of COVID19 (Coronavirus) on global poverty: why Sub-Saharan Africa might be the region hardest hit. Blog. The World Bank, Apr, 20

Mallapaty S (2020) How sewage could reveal true scale of coronavirus outbreak. Nature News in Focus 580:176-177

Martinez-Alvarez M, Jarde A, Usuf E, Brotherton H, Bittaye M, Samateh AL, Antonio M, Vives-Tomas J, D'Alessandro U, Roca A (2020) COVID-19 pandemic in West Africa. Lancet Glob Health 8(5):631632

Martins V, Shackleton CM (2019) Bushmeat use is widespread but under-researched in rural communities of South Africa. Glob Ecol Conserv 17:e00583

McNatt ZZ (2020) Addressing noncommunicable diseases among urban refugees in the Middle East and North Africa-a scoping review. Confl Heal 14(1):1-14

Medema G, Heijnen L, Elsinga G, Italiaander R, Brouwer A (2020) Presence of SARS-Coronavirus-2 RNA in sewage and correlation with reported COVID-19 prevalence in the early stage of the epidemic in the Netherlands. Environ Sci Technol Lett 7:511-516. https://doi.org/10.1021/acs.estlett.0c00357
Miller MJ, Loaiza JR, Takyar A, Gilman RH (2020) COVID-19 in Latin America: novel transmission dynamics for a global pandemic? PLoS Negl Trop Dis 14(5): 0008265

Mohamed A (2020) Bovine tuberculosis at the human-livestock-wildlife interface and its control through one health approach in the Ethiopian Somali pastoralists: a review. One Health 9:100113

Momberg DJ, Ngandu BC, Voth-Gaeddert LE, Ribeiro KC, May J, Norris SA, Said-Mohamed R (2020) Water, sanitation and hygiene (WASH) in sub-Saharan Africa and associations with undernutrition, and governance in children under five years of age: a systematic review. J Dev Orig Health Dis:1-28

Moyo I, Nshimbi CC (2020) Of Borders and fortresses: attitudes towards immigrants from the SADC region in South Africa as a critical factor in the integration of southern Africa. J Borderlands Stud 35(1):131146

Nachega J.B, Grimwood A, Mahomed H, Fatti G, Preiser W, Kallay O, Mbala PK, Muyembe JJT, Rwagasore E, Nsanzimana S, Ngamije D (2020a) From easing lockdowns to scaling-up community-based COVID-19 screening, testing, and contact tracing in Africa: shared approaches, innovations, and challenges to minimize morbidity and mortality. Clin Infect Dis:ciaa695. https://doi.org/10.1093/cid/ ciaa695

Nachega JB, Seydi M, Zumla A (2020b) The late arrival of COVID-19 in Africa-mitigating pan-continental spread. Clin Infect Dis 71(15): 875-878. https://doi.org/10.1093/cid/ciaa353

Nguyen VD, Sreenivasan N, Lam E, Ayers T, Kargbo D, Dafae F, Jambai A, Alemu W, Kamara A, Islam MS, Stroika S (2014) Cholera epidemic associated with consumption of unsafe drinking water and street-vended water-eastern Freetown, Sierra Leone, 2012. Am J Trop Med Hyg 90(3):518-523

Nkengasong JN, Mankoula W (2020) Looming threat of COVID-19 infection in Africa: act collectively, and fast. Lance 395(10227): $841-842$

O'Grady J, Hoelscher M, Atun R, Bates M, Mwaba P, Kapata N, Ferrara G, Maeurer M, Zumla A (2011) Tuberculosis in prisons in subSaharan Africa-the need for improved health services, surveillance and control. Tuberculosis 91(2):173-178

Oakenfull RJ, Wilson AJ (2020) Qualitative Risk Assessment: what is the risk of food or food contact materials being a source or transmission route of SARS-CoV-2 for UK consumers? Food Saf Agency (FSA)UK

Okullo JO, Moturi WN, Ogendi GM (2017) Open defaecation and its effects on the bacteriological quality of drinking water sources in Isiolo County, Kenya. Environ Health Insights 11: 1178630217735539

Pan Y, Zhang D, Yang P, Poon LLM, Wang Q (2020) Viral load of SARS-CoV-2 270 in clinical samples. Lancet Infect Dis 20:411412

Pansini R, Fornacca D (2020) Higher virulence of COVID-19 in the airpolluted regions of eight severely affected countries. MedRxiv Preprint. https://doi.org/10.1101/2020.04.30.20086496

Patwary MA, O'Hare WT, Sarker MH (2011) Assessment of occupational and environmental safety associated with medical waste disposal in developing countries: a qualitative approach. Saf Sci 49(8-9): 1200-1207

Phoku JZ, Barnard TG, Potgieter N, Dutton MF (2016) Fungal dissemination by housefly (Musca domestica L.) and contamination of food commodities in rural areas of South Africa. Int J Food Microbiol 217:177-181

Potgieter N, Aja-Okorie U, Mbedzi RL, Traore-Hoffman AN (2020) Bacterial contamination on household latrine surfaces: a case study in rural and Peri-urban communities in South Africa. In: Current microbiological research in Africa. Springer, Cham, pp 175-183

Pulsipher LM, Pulsipher A (2008) World regional geography: global patterns, local lives, 4th edn. W.H. Freeman and Company, New York, pp 353-411 
Pung R, Chiew CJ, Young BE, Chin S, Chen MI, Clapham HE, Cook AR, Maurer-Stroh S, Toh MP, Poh C, Low M (2020) Investigation of three clusters of COVID-19 in Singapore: implications for surveillance and response measures. Lancet

Randazzo W, Truchado P, Cuevas-Ferrando E, Simón P, Allende A, Sánchez G (2020) SARS-CoV-2 RNA in wastewater anticipated COVID-19 occurrence in a low prevalence area. Water Res 181: 115942. https://doi.org/10.1016/j.watres.2020.115942

Schlein L (2020) Overcrowding, Unhygienic Conditions Causing Quick Spread of COVID 19 in Prisons, UN Says. Available at: https:// www.voanews.com/covid-19-pandemic/overcrowding-unhygienicconditions-causing-quick-spread-covid-19-prisons-un-says. Accessed 8 June 2020

Shariatifar N, Molaee-aghaee E (2019) A novel coronavirus 2019 (COVID-19): important tips on food safety. J Food Saf Hyg 5(1): $58-59$

Shereen MA, Khan S, Kazmi A, Bashir N, Siddique R (2020) COVID-19 infection: origin, transmission, and characteristics of human coronaviruses. J Adv Res 24:91-98

Shi P, Dong Y, Yan H, Zhao C, Li X, Liu W, He M, Tang S, Xi S (2020) Impact of temperature on the dynamics of the COVID-19 outbreak in China. Sci Total Environ 728:138890. https://doi.org/10.1016/j. scitotenv.2020.138890

Sichewo PR, Vander Kelen C, Thys S, Michel AL (2020) Risk practices for bovine tuberculosis transmission to cattle and livestock farming communities living at wildlife-livestock-human interface in northern KwaZulu Natal, South Africa. PLoS Negl Trop Dis 14(3):e0007618

Siedner MJ, Gostin LO, Cranmer HH, Kraemer JD (2015) Strengthening the detection of and early response to public health emergencies: lessons from the west African Ebola epidemic. PLoS Med 12(3): e1001804. https://doi.org/10.1371/journal.pmed.1001804

Siminyu S, Swilling M, Cairncross S, Rheingans R (2017) Determinants of quality of shared sanitation facilities in informal settlements: case study of Kisumu, Kenya. BMC Public Health 17(1):68

Songe MM, Hang'ombe BM, Knight-Jones TJ, Grace D (2017) Antimicrobial resistant enteropathogenic Escherichia coli and Salmonella spp. in houseflies infesting fish in food markets in Zambia. Int J Environ Res Public Health 14(1):21

Tambo E, Ugwu EC, Ngogang JY (2014) Need of surveillance response systems to combat Ebola outbreaks and other emerging infectious diseases in African countries. Infect Dis Poverty 3(1):29

Tilley E, Ulrich L, Luthi C, Reymond P, Zurbrügg C (2014) Compendium of sanitation systems and technologies, 2nd revised edition. Dübendorf, Switzerland: Swiss Federal Institute of Aquatic Science and Technology (Eawag). https://www.eawag.ch/en/ department/sandec/publications/compendium/ Accessed 8 June 2020

Tosepu R, Gunawan J, Effendy DS, Lestari H, Bahar H, Asfian P (2020) Correlation between weather and Covid-19 pandemic in Jakarta, Indonesia. Sci Total Environ 725:138436

Truong TD (2005) Poverty, gender and human trafficking in sub-Saharan Africa: rethinking best practices in migration management. UNESCO. Available at: http://us-cdn.creamermedia.co.za/assets/ articles/attachments/02542_poverty1432e.pdf. Accessed 29 May 2020

UN (United Nations) (2020) COVID-19: UN teams step up efforts to protect rights in prisons, as revolts intensify worldwide. https:// news.un.org/en/story/2020/05/1063292. Accessed 10 June 2020

Van Doremalen N, Bushmaker T, Morris DH, Holbrook MG, Gamble A, Williamson BN, Tamin A, Harcourt JL, Thornburg NJ, Gerbe SI, Lloyd-Smith JO, de Wit E, Vincent J, Munster VJ (2020) Aerosol and surface stability of SARS-CoV-2 as compared with SARSCoV-1. N Engl J Med. https://doi.org/10.1056/NEJMc2004973

Vaughan A (2020) Some African countries begin to ease coronavirus lockdowns. New Sci 246(3282):13
Velavan TP, Meyer CG (2020) The COVID-19 epidemic. Tropical Med Int Health 25(3):278

Wang J, Tang K, Feng K, Lv W (2020) High temperature and high humidity reduce the transmission of COVID-19. https://arxiv.org/ ftp/arxiv/papers/2003/2003.05003.pdf. Accessed 10 June 2020

Whitworth JA, Kokwaro G, Kinyanjui S, Snewin VA, Tanner M, Walport M, Sewankambo N (2008) Strengthening capacity for health research in Africa. Lancet 372(9649):1590-1593

WHO (World Health Organization) (2020a) Infection Prevention and Control for the safe management of a dead body in the context of COVID-19, Interim guidance 24 March 2020. World Health Organization, Geneva

WHO (World Health Organization) (2020b) Modes of transmission of virus causing COVID-19: implications for IPC precaution recommendations. https://www.who.int/news-room/commentaries/detail/ modes-of-transmission-of-virus-causing-covid-19-implications-foripc-precautionrecommendations. Accessed 5 May 2020

WHO (World Health Organization) (2020c) Novel coronavirus - $\mathrm{nCoV}$ 2019. https://www.who.int/emergencies/diseases/novelcoronavirus-2019.

WHO (World Health Organization) (2020d) New WHO estimates: up to 190000 people could die of COVID-19 in Africa if not controlled. https://www.afro.who.int/news/new-who-estimates-190-000people-could-die-covid-19-africa-if-not-controlled. Accessed 8 June 2020

WHO (World Health Organization) (2020e) Water, sanitation, hygiene and waste management for COVID-19. https://apps.who.int/iris/ bitstream/handle/10665/331499/WHO-2019-nCoV-IPC WASH2020.2-eng.pdf? sequence=1\&isAllowed=y. Accessed 10 June 2020

Wu Y, Guo C, Tang L, Hong Z, Zhou J, Dong X, Yin H, Xiao Q, Tang Y, Qu X, Kuang L, Fang X, Mishra N, Lu J, Shan H, Jiang G, Huang X (2020a) Prolonged presence of SARS-CoV-2 viral RNA in faecal samples. Lancet Gastroenterol Hepatol 5:434-435. https://doi.org/ 10.1016/S2468-1253(20)30083-2

Wu Y, Jing W, Liu J, Ma Q, Yuan J, Wang Y, Du M, Liu M (2020b) Effects of temperature and humidity on the daily new cases and new deaths of COVID-19 in 166 countries. Sci Total Environ 729: 139051. https://doi.org/10.1016/j.scitotenv.2020.139051

Wurtzer S, Marechal V, Mouchel JM, Moulin L (2020) Time course quantitative detection of SARS-CoV-2 in Parisian wastewaters correlates with COVID-19 confirmed cases. medRxiv

Yao Y, Pan J, Liu Z, Meng X, Wang W, Kan H, Wang W (2020) No association of COVID-19 transmission with temperature or UV radiation in Chinese cities. Eur Respir J 55(5)

Yeo C, Kaushal S, Yeo D (2020) Enteric involvement of coronaviruses: is faecal-oral transmission of SARS-CoV-2 possible? Lancet Gastroenterol Hepatol 5(4):335-337

Yiougo L, Koanda H, Luethi C, Wéthé J (2011) Application of the material flow analysis method for evaluating strategic sanitation plan in sub-Saharan Africa: the case of Fada N'Gourma-Burkina Faso. Water Sci Technol 63(11):2498-2504

Young BE, Ong SWX, Kalimuddin S, Low JG, Tan SY, Loh J, Ng OT, Marimuthu K, Ang LW, Mak TM, Lau SK (2020) Epidemiologic features and clinical course of patients infected with SARS-CoV-2 in Singapore. Jama 323(15):1488-1494

Zhang D, Ling H, Huang X, Li J, Li W, Yi C, Zhang T, Jiang Y, He Y, Deng S, Zhang X (2020) Potential spreading risks and disinfection challenges of medical wastewater by the presence of severe acute respiratory syndrome coronavirus 2 (SARS-CoV-2) viral RNA in septic tanks of Fangcang hospital. Sci Total Environ 741:140445

Zume JT (2011) Risks of burial practices on groundwater quality in rural north-Central Nigeria. J Water Health 9(3):609-616

Publisher's note Springer Nature remains neutral with regard to jurisdictional claims in published maps and institutional affiliations. 